\title{
Critiquing of the 'Operation Mechanism of the Driving Force System of Ecosystem of Cyber-Society Based on the System Dynamics'
}

\author{
Article by Ikechukwu F. Ezeugo \\ PhD., Information Technology, Texila American University \\ E-mail:iykye@yahoo.com
}

\begin{abstract}
This research project is purposed for critiquing an academic work that centres on the dynamics of the emerging cybersociety phenomenon driven by the influences of ICT innovations on society and its sociocultural systems. The original research work being critiqued is titled: 'Operation Mechanism of the Driving Force System of Ecosystem of Cyber-Society Based on the System Dynamics'. The work investigated the ecosystem of the Cybersociety phenomenon with the aim of enriching the body of knowledge with an understanding of the operation mechanism of its driving Force System; the Authors considered the ecosystem operation mechanism with reference to system dynamics operating principles. The project result is intended to close the knowledge gaps surrounding the growing interest of the research community in understanding the internal and external forces that stimulate the development, growth, and sustenance of the visible effects of the Cybersociety phenomenon and its ecosystem. The relevance of the study is underlined by the need for deeper scientific insights into the factors that are responsible for the evolution and thriving of the cybersociety phenomenon within the existing societal frameworks which are also fast redefining contemporary society and general lifestyle. This work is aimed at producing a systematic and objective review of the original research for the purpose of highlighting its strengths and weaknesses, and its applicability in real life practice. The project's output value and contributions to the body of knowledge is founded on the need to satisfy the urgent requirements for professionals, academics and industry practitioners to be equipped with empirical evidence of the validity and reliability of a published material obtained through scientific means involving detailed peer review. In delivering its goals, this project will use empirical research methods for assessing the critiqued article, and synthetization of published materials of evidential values to critically evaluate the published research work for a knowledgeable evaluation report.
\end{abstract}

Keywords: Cyberculture, Cybersociety ecosystem, System dynamics, Driving forces, Operating Mechanism, Article Review, academic critiquing, Networks Sociology, Social Ecology, information age, societal structures, self-determination theories, self-regulation theory, Article stability.

\section{Introduction}

Operation Mechanism of the Driving Force System of Ecosystem of Cyber-Society Based on the System Dynamics is a research project report published by Xiaolan Guan, Zhenji Zhang, and Shugang Zhang in 2013. It was published in the International Journal of Computers, Communications \& Control. Whereas the focus of the original work is on the dynamics of the cybersociety ecosystem and the mechanisms of its driving forces, this very tributary research work is focused on consolidation and extension of academic works on the subject. This is achieved through the critiquing of the original work undertaken in the context of academic article review project. This is by nature a second-degree empirical study of the research subject as proposed by the original Authors. It involves a critical review of the initial research report, and methodical assessment of the research processes alongside the obtained results and the authors' extrapolations. Article critiquing as an academic project is generally achieved through synthetization of the original work alongside other related publications to find materials of evidential value for benchmarking the critiqued work's findings against submissions from other authorities. The report of this work will of necessity appear different form the generic research reports because findings are presented following the structures and standard for academic article review and critiquing projects.

In line with the requirements for critiquing research works that are tailored as in-depth article review based on tributary research, the report presentation commences with a description of the source of the article; this is followed by an introduction (this section); then, analysis of the critiqued article research 
ISSN: $2520-3088$

processes which includes assessment of the depth of the original article's review of related literatures, the article's summary, the analysis of the paper presentation structures, detailed critiquing of the authors' submissions; and conclusion based on the tributary research findings. Additionally, this also methodically examine the article for an in-depth insight into the article's structures and the effectiveness of the Author's presentation. The examination is on the basis of the background of the setting out of the report content; the objective is to determine if a normal academic article reader can read and understand with minimal efforts, even from a non-technical perspective (taking each material presentation on its face value). In achieving the above, the reviewed article was examined following its declared plan as indicated in its title and elaborated in the abstract section; also, this was evaluated alongside the significances of the Author's submissions to determine the validity of the report presentation method. Using empirical evidence from a second-degree research work undertaken for this purpose, the article was further judged on the strength of its own review of existing literatures in its subject domain. The Authors' authorities were examined, and the accuracy of the presented facts was also tested alongside the currency of the research subject and the used materials. The overall relevance of the research work and the significances of its submissions to relevant bodies of knowledge were examined together with the objectivity of the Author's arguments. The right application of graphs, charts, tables and images in the article was also assessed. The article's stability was x-rayed together with its alignment with recent developments in related areas. From my assessment, the article is generally above-board in its research methods, its contents layout, logical alignment of its points, and its presentation style is excellent. However, the substance of the report and allusion to critical facts that should have formed empirical proofs of the Authors' simplifying assumptions remain substantially arguable and not with convincing quantitative scientific detail relevant in the domain of study.

For relevance and applicability purposes, it is important to note that apart from a structured extension of the original research work from a critiquing perspective; reviews of this nature are particularly for applications in the knowledge construction domain. Its relevance is underlined by the fact that it is an independent authenticating second degree research work purposed for providing practical demonstration of how academic critiquing works can be taken beyond head-knowledge, but through an in-depth tributary research works particularly structured for enriching researchers understanding of the peculiar requirements and industry expectation in carrying out original research works and in presenting research reports that meet global academic standards. In this, a practical example is made of a real work to demonstrate the nature and structures of academic works critiquing while still extending the breadth and depth of the original work with a view of providing additional body of knowledge from a critical and objective perspective that can be relied upon for judging the validity of the work with respect to its processes, findings and submissions.

\section{Research question}

The research question bothers on whether the article titled 'Operation Mechanism of the Driving Force System of Ecosystem of Cyber-Society Based on the System Dynamics' meets academic project's report quality, accuracy, validity and reliability standards measured in the context of academic article critiquing. This is tested through empirical studies involving direct assessment of the article and benchmarking of findings against standards and submissions from other authorities.

\section{Materials and methods}

Empirical research method is the study approach adopted for this project. Empirical evidence was gathered through direct assessment of the critiqued article, and benchmarking of the findings against critique's experiences, and deductions from other related published materials with evidential value synthesized in the course of the project. The critiqued article was directly assessed, analysed and dissected by the researcher using scientific standards for measuring academic research and report presentations. Findings were qualitatively analysed using data gathered from the article as the primary data source and triangulated with data gathered from the synthetization of related published materials from journals, mass media, and textbooks as the secondary data sources. The research question bothers on the quality of the article which is a factor of its accuracy, validity, objectivity, currency, authority, and reliability.

A unique value that this work adds to the body of knowledge includes the fact that it directly measures the quality of the critiqued article in a repeatable form using established standards as against the dogmatic doctrines of accepting and relying on an academic article because it is published in a popular journal, or 
because it has the look and feel of an academic report from its presentation face value and use of language. This is based on the fact that the article and its submissions are judged with knowledge arising from empirical evidence gathered specifically using practical repeatable approaches, and experience measured against scientific standards. Achieving this involves academic rigor, in-depth analysis of the original work, and accumulation of data for judging each component of the report against the industry requirements. Results are presented in a descriptive form under each subject of the specific requirements of standards for academic works reporting. These are presented as the Critique's assessment of the original articles in sections like literature review (for example) which is meant to judge the article's presentation of what is currently known about the researched topic. Other sections include assessment of the research design or methodology, results - sometimes referred to as "findings" and so on. Because of the depth of this kind of reviews, the critiquing report is usually larger than the original work in volume.

\section{Results: review of literature}

Within its limitations, the article has a stylish literature review fully embedded in its introduction section. As a prologue to the literature review, the authors remarked that the study and its perspective is a new research area and therefore literatures that have direct and total view of the research subject are not yet available as at the time of the research. The article, therefore, identified that available related materials relevant to the study are focused on two core secondary areas: the sociology of network and social ecology. It further observed that those focused on the study of sociology of network are also split into two main school of taught: those advocating its classification as part of information science, and those advocating for its classification under media and dissemination for reasons of its unique features that deeply intertwined with media and dissemination. Still on the side of sociology of network, the 2001 Rise of the Network Society published by Custer M. through the Social Science Academic Press (China) was used to establish the interest of researchers on the emerging network society which will eventually become the present-day Cybersociety. Also, to make allusion to the opinions of some school of taught which Custer M. Belongs, Custer's perception of the networked society was reported as follows: “...a new social form of society that is different from the reality, ...characterized by social forms than the superiority of social action" (Guan X., Zhang Z., and Zhang S. 2013). The 2003 publication of Gong Qi titled 'Essence of the Networking Society: A Digitalization Social Relationship Structure' added to the evidence of researchers' recognition of the emerging new social order, though with a more simplified definition captured in the following words: "a virtual space of human and humans life, study and work in this alternative space" (Guan X., Zhang Z., and Zhang S. 2013).

Comparing the age of the two divisions, the article asserted that research works on social ecology found in the course of the study point to the fact that this aspect may have started much earlier than that of the sociology of network. The 1979 work of American Cornell University's Brown titled, 'Ecology of human development' was exhumed probably to put the work in context with the natural ecology and also to support some of the Authors' claim on human activities in social networks for supporting their basic assumptions. In attempt to categorize developments in the research subject's domain, the article asserted that research in this area has crystallized into the following two key directions:

1. Analysis of the human social life through related theories and methods of natural ecology that bothers on human activities, social development, etc.

2. Investigation of the coordinated development between the society, economics and resources, taken from the quantitative and qualitative dimensions rooted on the theory of ecology.

The first group which focused on the analysis of the human social life through related theories and methods of natural ecology was collectively supported with two 2004 Harvard Business Review material titled 'Strategy as Ecology', and 'The Keystone Advantage: What the New Dynamics of Business Ecosystems Mean for Strategy, Innovation, and Sustainability' written by Iansiti, M., and Levien, R. The second group which focused on the investigation of the coordinated development between the society, economics and resources was supported with a 2010 Beijing Jiaotong University publication by Feng J. titled 'Research on the Coordinated Development between Internet Uses and Network Environment of the Ecosystem of Cybersociety'; and an International Journal of Computers, Communications \& Control, publication written by Cubillos C., Donoso, M., Rodriguez N., GuidiPolanco F., and Cabrera-Paniagua D., titled: 'Towards Open Agent Systems Through Dynamic Incorporation'; and also, the Neghina, D., Scarlat, E. 2013 publication titled: 'Managing Information 
DOI: 10.21522/TIJAR.2014.SE.19.01.Art011

ISSN: $2520-3088$

Technology Security in the Context of Cyber Crime Trends'. The authors insisted that the driving force system of Ecosystem of Cyber-society concept as proposed is a cross-subject research between sociology of network and social ecology, particularly as it emphasizes analysis of the network space from a sociological perspective in addition to providing a reflection of the theory of system dynamics in the ecology. Notwithstanding, the authors considered the 2008 'Ecosystem of Cyber-society' by Zhang Z., Zhang R. (which appears to be their earlier work) as significant to their present work in this subject.

Overall, sixteen (16) articles were listed to have been consulted in the cause of the research. The paper's in-line citations which depicted the referenced literatures with numeric values were appropriately applied and corresponding numeric values were rightly placed against the particular materials they were meant to represent in the reference section. The article's literature review is smart and also readable.

\section{Article summary}

The article presented a report of a research project titled: Operation of the Driving Force System of Ecosystem of Cyber-society Based on the System Dynamics. In the report, the driving force system of Ecosystem of Cyber-society is analyzed using the theories of system dynamics. The researcher's goals were encapsulated in addressing their perceived need of a scientific mechanism of intervention and regulation in the Ecosystem of the emerging Cybersociety for the purpose of:

1. Solving the integration problem of different organizations and forces influencing the ecosystem of Cyber-society;

2. Reducing the Cyber-society evolution processes and harnessing the driving force system to ensure synchronization and orderliness in the operation of the driving force system of ecosystem of Cybersociety.

3. Strengthen the driving forces to enhance the formation and speedy development of the ecosystem of Cybersociety.

The article made a good attempt at delivering in the above goals by analyzing the driving force system of ecosystem of Cyber-society through what looks like a superimposition of the theory of System Dynamics. The paper's final delivery is the Authors' proposition of a basic theoretical framework of the driving force system of ecosystem of Cybersociety with what it termed a systematic presentation of the ecosystem's operation mechanism using the theory of System Dynamics. In analyzing their concept of the driving force system of ecosystem of Cybersociety, the Authors opined that driving force system is constituted into three main categories, namely:

a) The subsystem of driving forces;

b) Stimulate subsystem of driving forces;

c) Carrier subsystem of driving forces.

The article construed the driving force system to be "a virtual manual system with the characteristics of integrity, structure hierarchy, orderliness and openness" (Guan X., Zhang Z., and Zhang S. 2013). In describing the operation mechanism of the driving force system, the article averred that it is a combination of push and pull, organization and conduction, Integration and collaboration, and innovation and development mechanisms. However, the article's presentation of the above postulations and their proofs do not seem to have followed simple intuitive logics. For example, it is illogical to have the subsystem of driving forces as a different category from the stimulate subsystems of driving forces and carrier subsystems of driving forces in their outlining of the categorization of the concepts of the driving force system of ecosystem of Cybersociety. If a category is named the subsystem of driving forces, it is only logical that every other category construed to be part of that subsystem to come under that category instead of having stimulated and carried subsystems being placed independent of the primary subsystem. In this light, the framework should have looked like the representation in figure 1 below: 


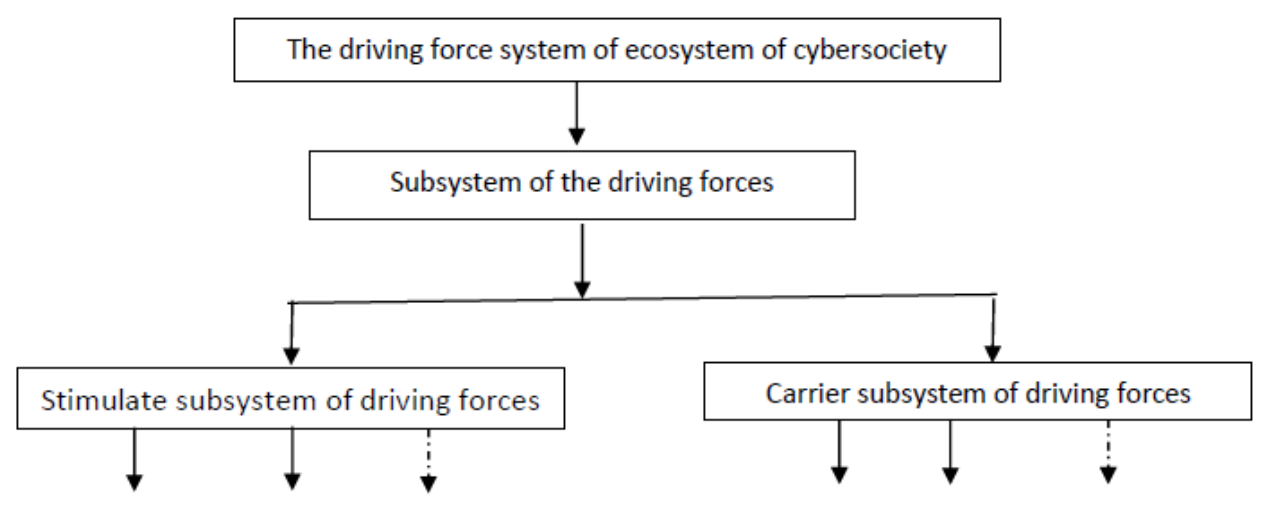

Figure1. Alternative: Atheoretical framework of the driving force system of Ecosystem of Cyber-society

In its conclusion, the article submitted that the formation and development of Ecosystem of Cybersociety is the function result of different driving forces that work together in a combined mode to control the formation and development of Ecosystem of Cyber-society (Guan X., Zhang Z., and Zhang S. 2013). Whereas the above concluding submission seems insightful and logical, the presumption about the dynamics and operating mode of these different driving forces working together to control the formation and development of Ecosystem of Cybersociety seem somewhat shallow and without detailed quantitative analysis for their scientific proof. Presumably, the operating principles of these driving forces and their dynamics are captured in the Authors' description of the system as a virtual manual system. However, it appears to me that a more accurate description of this operation is that of a Self-determination/regulation theory as applied to nature and autonomy in higher order social organizations. Therefore, my argument is that the functioning of the driving force systems of the ecosystem of cybersociety is more aligned to Nature and Autonomy theory instead of the Manual and Control theory as suggested by the Authors.

Conceptually, the above submission of Sherry is not far from the interactions between today's society and the evolution of the internet with its innovative solutions that have caused the cybersociety phenomenon to emerge and thrive, even to the extent of making its ecology an important research subject. Clearly, it is apparent that the paper under review assumed that the formation and development of Ecosystem of Cybersociety operates by a coordinated manual control principle. The implication is that a consciously coordinated manual effort is required to control all or most of the driving forces in order to advance and hasten the development of the Ecosystem of the emerging internet mediated Cybersociety. Contrarily, the emergence and sustenance of the cybersociety phenomenon and the thriving of its ecosystem are collectively predicated on present-day ICT evolutions and contemporary society's willing embrace of the innovations for their apparent usefulness and all-encompassing value additions to living in modern times. Whereas proofs of coordinated combined regulation of the influencing factors in the whole operation are still lacking, the compliance of the individuals' rolls to the Self-Regulation Theory is not in doubt. I make the above submission in view of the fact that internet usage is arguably the key driving force behind the emergence of the Cybersociety phenomenon, and also the fact that the attitudes and habits of individuals in their conscious use of the internet in meeting their various needs play very significant roles in the sustenance and thriving of the concept. In demonstrating the influence of the selfregulation theory in Internet Usage, Robert LaRose, and Matthew S. Eastin averred that self-regulation has emerged as an important predictor of Internet consumption. They further submitted that "The selfregulatory mechanism describes how individuals continually monitor their own behavior (selfmonitoring), judge it in relation to relevant personal and social standards (judgmental process), and apply self-reactive incentives to moderate their behavior (self reaction). Self-regulation is an important point of distinction between SCT and "functionalist" or stimulus-response theories of human behaviour in that it describes self-generated influences that free the individual from blindly following the dictates of external reinforcement. ...Self-regulation may normally be expected to moderate media consumption. (LaRose R., and Eastin M. S., 2002). Now, that leaves us with the question whether individual of the $21^{\text {st }}$ century can be truly said to have been blindly following the dictates of external reinforcement in their use of the internet for creating and participating in virtual communities that have become part of their daily living? All the same, the Authors have done excellently well in opening a new horizon of research that will 
DOI: 10.21522/TIJAR.2014.SE.19.01.Art011

ISSN: $2520-3088$

stimulate cross-disciplinary empirical investigations for finding suiting answers to the critical questions about the operations of the driving force systems of the ecosystem of cybersociety raised by reason of their work in this project.

\section{Article structure}

Principal among the things considered in assessing the article structures are Contents Alignment, Presentation Format, Intuitiveness and Logical Flow of Information as necessary in academic papers. As expected, the report presentation started with the research subject title followed with identification of the Authors and indication of their authorities through their institutional affiliations. As usual, the abstract was introduced immediately after the listing of the Authors' institutional affiliation. The abstract presented the research goals with a summary of what was finally achieved as analysis of the driving force system of Ecosystem of Cyber-society using the theory of System Dynamics, proposition of a theoretical framework, and presentation of its operation mechanism in a methodical way. The abstract was also followed by section 1 (introduction) of the report which presented the report Introduction and literature review reports. Section 2 was featured with a proposition of the theoretical framework of the driving force system of Ecosystem of Cyber-society. Section 3 followed with the analysis of the operation environment and formation process of the driving forces. Section 4 was next with the operation mechanism of the driving force system presented. Section 5 had the paper conclusion, followed by acknowledgement and bibliography which listed the materials consulted in the course of the work. Apparently, the article is well organized in its presentation structures as the article structures and contents are rightly aligned in a manner that makes a good read.

\section{Discussions}

\section{Article critique}

\section{Authority}

This article was published in the International Journal of Computers, Communications \& Control (IJCCC) which is the journal publishing arm of the Romanian Agora University. IJCCC was founded in 2006 with ISSN 1841-9836. As indicated in the name, IJCCC publication interest centres on Computers, Communications \& Control. With respect to indexing coverage, IJCCC is covered by THOMSON REUTERS and is indexed in ISI Web of Science Knowledge. Also, IJCCC is indexed by SCOPUS under the following Subject Categories: Computational Theory and Mathematics, Computer Networks and Communications, and Computer Science Applications. As an indication of the acceptance of IJCCC journal publishing control policies and commitment to excellence, IJCCC was nomination by Elsevier for the 2015 Romanian Journal Excellence Award. Also, "IJCCC is in Top 3 of 157 Romanian journals indexed by Scopus (in all fields) and No.1 in Computer Science field: Elsevier/ Scopus" (univagora.ro, 2016). IJCCC is a member of the Committee on Publication Ethics (COPE) by whose principles it also abides.

In addition to the above, the Authors' authority is primarily established by the Authors' affiliation with the Beijing Institute of Graphic Communication, School of Economics and Management, and Beijing Jiaotong University, School of Economics and Management, China. However, details of the Authors academic qualifications, fields of study are not indicated. All the same, if the Authors do not have the basic qualifications, the project would not have received the sponsorship of General Research Project (18190113002) and the Quality Improvement Project of Personnel Training (03150113016) of Beijing Municipal Education Commission, and that of the Institute Level Project (E-b-2012-20) and the Course Construction Project (22150112088) of Beijing Institute of Graphic Communication (Guan X., Zhang Z., and Zhang S. 2013).

\section{Accuracy}

The article was published in 2013 with sixteen listed references, half of the referenced materials have their publication dates spanning from 2007 to 2013. From the beginning, the Authors stated that the project is exploring a new research area of which the chances of finding materials with direct bearing to its research problem is very slim. Notwithstanding, there is no obvious lack in paper's citation accuracy all referenced materials were appropriately cited in-text and also listed fully in the reference section.

On the other hand, report structures and presentation procedural accuracy is attested to by reason of the fact that the article is published in a regulated academic publishing platform of high repute IJCCC, and 
also further assured by the fact that the research is partially sponsored by research oriented organizations; therefore, the organizations' due diligence processes and the publisher's strict editorial and approval procedures must have worked together to reasonably assure the paper's accuracy.

However, accuracy of material facts and simplifying assumptions is highly subjective and difficult to conclusively ascertain in the early stage of the article's subsistence, particularly for research work that is said to have no previous literatures focusing in its research subject where with the submissions and results can be benchmarked. This is more so as the logics, experimental proofs, and arguments raised in the paper must of necessity be subjected to critical review by authorities in the field. In the light of the above, it is imperfective that I present my reservations against some of the submissions of the paper as already raised in other sections of this review. Major part of these observations includes the objection earlier raised in the summary section concerning the structuring of the framework produced by the paper as part of its deliverables. This is in addition to the objection raised about the paper's suggested operating principles of the driving forces as a virtual manual system in which I opined that it is more of a Self regulation theory as applied to nature and autonomy principles.

Ostensibly, accessible internet, mobile ubiquity, affordable communication devices, idiot-proof innovative networking, transaction, informative and communication platform solutions, and the subsisting human needs for conformity, efficiency and convenient living which resulted into unprecedented embrace of the numerous solutions offered by ICT innovations are the key driving forces behind the emergence, sustenance and thriving of the Cybersociety phenomenon and its ecosystem.

As the internet has transformed the traditionally isolated parchments of communities that made up the wide world into a global village, cybersociety emergence and the evolution of its ecosystem has technically defiled the theory of strong dependency on economy, politics and culture. Possibly, there may be basis to argue that the influence of economy is not completely broken; however, such residual influence must be a very limited one and also predominantly operating skeletally at individual levels. Nevertheless, political and cultural factors have since lost their grips as driving forces of the ecosystem of cybersociety with any significant influence. The above fact became more apparent during the 2011 Arab Spring social media revolution (Gire S. 2014) where a stronger, more resolute, united, coordinated and powerful society emerged from the cyberspace to redefine the polities, economy and culture of a whole region with known thriving economy, strong political structures and most reserved cultural heritage.

There is no better proof of the cybersociety pre-eminence in contemporary society, or better test of the robustness and thriving of its ecosystem than that demonstrated in the Arab spring. Certainly, researchers can never make an end to the discovering of the principal factors and the dynamics of this phenomenon (Cybersociety) which started from the more liberal American and English society to traverse through the entire world - ravaging the very conservative Arab cultures, spreading over to even the poor African society without skipping the uptight Asian cultures, Japan, China and Korea inclusive. Therefore, juxtaposing the observations against the below submission of the paper leaves more for argument: "Only if the force of economics, politics and culture can complement with each other, coordinate their actions and optimize the allocation of various needs and interest pursuit of the subjects of Ecosystem of Cybersociety, then it can give appropriate positive driving force to the formation and development of Ecosystem of Cyber-society, and thus effectively promote the formation and development of Ecosystem of Cyber-society" (Guan X., Zhang Z., and Zhang S. 2013). Contrarily, availability and accessibility of TECHNOLOGY (Internet, gadgets and devices, platforms, software and applications), Needs and Desires of the People (social networking, interacting, communication, and transaction) alongside Societal Institutional Pressures (social media, e-banking, e-governance, e-services, e-education, ecommerce, etc.) and Individuals' Attitudes and Habits (dispositions and the influence of selfdetermination theories (SDT) in usage) are showing up as the true key driving factors as the cybersociety phenomenon continues to evolve.

Invariably, if the above is anything to go by, the validity of the bellow submission of the paper will require further examination: "Only through the coordination between the driving forces within and outside the system, then it can generate new driving force structures and joint force, improve the operation efficiency of the driving force system, and thus promote the fast forward development of Ecosystem of Cyber-society with its powerful functions" (Guan X., Zhang Z., and Zhang S. 2013). The sustenance of the cybersociety phenomenon or the evolution of its ecosystem is no longer being occasioned or sustained by coordinated manually controlled mechanisms preserved by efforts of any 
ISSN: $2520-3088$

government. We have seen cases of some governments trying to prevent their citizens from free access to internet, we have also seen situations where some social activists try to discourage people from using the internet $\mathrm{n}$ a certain manner, and some technology companies trying to withhold or delay products' release or innovation, yet, none of these have significantly impacted the evolution or growth of the cybersociety phenomenon. Rather, what seems to have a measurable influence is the self-regulation theory in usage. In demonstrating the influence of the self-regulation theory in Internet Usage, Robert LaRose, and Matthew S. Eastin averred that self-regulation has emerged as an important predictor of Internet consumption. They further submitted that "The self-regulatory mechanism describes how individuals continually monitor their own behavior (self-monitoring), judge it in relation to relevant personal and social standards (judgmental process), and apply self-reactive incentives to moderate their behavior (self reaction). Selfregulation is an important point of distinction between SCT and "functionalist" or stimulus-response theories of human behavior in that it describes self-generated influences that free the individual from blindly following the dictates of external reinforcement. ...Self-regulation may normally be expected to moderate media consumption. (LaRose R., and Eastin M. S., 2002).

\section{Originality and referencing for non-original ideas}

A logical indication of the originality of the research project's pursuit is readily seen in the paper's declaration that "...there is still not much comprehensive and systematic research about the cyber-society from the perspective of ecosystem. And there is no literature that has proposed the concept ...related research mainly focuses on the sociology of network and social ecology"(Guan X., Zhang Z., and Zhang S., 2013). This is further underlined by the arguments that I have so far raised on the authors' submissions. Also, in carrying out this research, many academic materials were consulted and there are no indications that due credits were not given to the owners of the intellectual materials by way of appropriate referencing.

\section{Currency}

The article was written in 2013, about four years ago as the time of this review. The research problem it was focused on addressing is about deepening understanding of the ecosystems of the emerging cybersociety as an extension of existing works on the sociology of network and social ecology of the information age. Its objective is to propose the concept of driving force system of Ecosystem of Cybersociety with a methodical analysis of its mechanisms. Evidently, this is still a current research problem whose relevance is also not in doubt. Besides, there is yet no indication that the research problems bothering on understanding of the evolving cybersociety and the driving forces of its ecosystem, their mechanisms and operating principles have sufficiently been resolved. In fact, as cybersociety continue to evolve defying established sociological theories, political formations and restraining laws to break through ancient traditional institutions and cultural boundaries, the knowledge gaps in this area has continued to be more obvious and curiosity in the research cycle has also continued to grow as many pertinent questions are yet to receive globally accepted matching answers. Majority of the materials referenced in the article are still current, others are original materials that are effectively dealing with the certain fundamental theories touching the subject matter with timeless intrinsic values.

\section{Relevance}

International Journal of Computers, Communications \& Control (IJCCC) in which the article was published was founded about eleven years ago and it is operated by the Romanian Agora University. It has continued to host many academic materials of high repute in the specialized areas of Computers, Communications \& Control. IJCCC publications are indexed in THOMSON REUTERS and SCOPUS under very important categories of information and communication technology. As a mark of the collective relevance of IJCCC published materials and excellence in their operations, IJCCC was nominated by Elsevier for the 2015 Journal Excellence Award, Romanian. Additionally, JCCC is listed as number three (3) of the one hundred and fifty seven (157) Romanian journals indexed by Scopus in all fields, and it is the number one (1) in the field of Computer Science. The article was published about four years ago (2013) as a complete research paper, not a company's whitepaper meant to promote a particular organization's product and service, also, it is not a literary art work designed to entertain.

Importantly, the cybersociety phenomenon is a recent development which has continued to evolve defying all known sociological theories, political formations and restraining laws to break through ancient traditional institutions and cultural boundaries; yet, the understanding of its ecosystem's dynamics does 
not appear to be growing in the same speed and dimensions. The fact that I have challenged some of the key submissions of the article notwithstanding; the propositions are my personal opinion which are subject to critical analysis by other experts. Nevertheless, the work has its relevance as it has opened a new horizon of research interest in an emerging subject area. Also, the relevance of this work is further underlined by the fact that this research project accurately aligns with the core issues surrounding the understanding of the key driving forces and the mechanisms behind the evolution of Cybersociety ecosystems. Another indication of the relevance of the work is the sponsorship granted by the General Research Project (18190113002) and the Quality Improvement Project of Personnel Training (03150113016) of Beijing Municipal Education Commission, and that of the Institute Level Project (E-b2012-20) and the Course Construction Project (22150112088) of Beijing Institute of Graphic Communication.

\section{Objectivity}

In most cases, the presentation of facts in support of the Authors' propositions indicates a balanced developed opinion. An instance is the authors' submission stating that: "The driving forces that affect the formation and development of Ecosystem of Cyber-society are not chaotic. However, they are an organic whole with a multi-level structure. The formation and development of Ecosystem of Cyber-society are driven by the driving forces that interact and constraint with each other, and ultimately form the multilayered driving force system" (Guan X., Zhang Z., and Zhang S., 2013). In confirming the above alongside the pressing need for a new theory that methodically analyze the formation mechanism of the cyber-society ecosystem and the associated problems, excerpts from science-definition.com affirmed the objectivity of this paper, even in its presentation of cyber-society as an emerging social form created by information technology innovations. More so, in its description of the phenomenon as: "a huge complex system, which is composed of cyber-society resources, cyber-society communities and related cybersociety environment and achieves the dynamic balance under the interaction between these elements. It emphasizes the interrelationships and integrity between the various elements in this large-scale system. It is not an isolated form of society, but rather the evolution of traditional society in the new information age. It retains parts of the traditional factors, but also demonstrates completely different new features" (science-definition.com 2017).

\section{Stability}

Since after the paper was published in 2013 , there is not yet an evidence of retraction of any of the Authors' claims, or publication of new editions or versions with the intent of making corrections, clarifications or significant additions to the material facts submitted by the authors in the article. The above is in addition to the fact the article's source is a journal operated by an internationally recognized institution of higher learning that has been a stable source of academic journals for the past 11 years holding a very large academic database in very specialized areas. Therefore, there is no evidence of lack of stability on the part of the article.

\section{Analysis of graph/Image/Table}

The article made reasonable use of illustrative figures/ images, a graph and a table in its presentation. Figure 1 graphically presented the theoretical framework of the driving force system of Ecosystem of Cyber-society proposed by the Authors which also is in the core of the solution promised by the paper. Figure 2 presented the function process of the stimulate subsystem of driving forces of Ecosystem of Cyber-society as proposed by the authors. Figure 3 was used to illustrate the operation lifecycle of driving force system of Ecosystem of Cyber-society while Figure 4 illustrated the composition forces model of the formation and development of Ecosystem of Cybersociety; the paper described this as the 'development stages of ecosystem of cybersociety'. Figure 5 served for illustrating the interactions between the driving forces and the environment of ecosystem of cybersociety, and it is presented with the title: 'Cross combination of driving forces to the formation of Ecosystem of Cyber-society'. Figure 6 illustrated the interaction between the hierarchy structures of the driving forces and the institutional collaboration functions, and it was titled: 'Organizational conduction of driving forces to the formation of Ecosystem of Cybersociety'. Table 1 apparently showed the Contents of the mechanism of integration and collaboration of driving force system of Ecosystem of Cyber-society (EC). 


\section{Alignment with contemporaries and recent advances in the subject area}

There is no doubt about the fact that the cybersociety ecosystem is made of a mixture of participants that interact for multiple purposes just as in the natural ecosystems of the physical society. Exploring understanding of the functioning of the driving forces for a healthy resilient, more efficient and satisfying cyber ecosystem, and also to enable preventive and defensive courses of action to be coordinated within and among communities of devices and users is the goals of this paper. Given the Author's description of this as a new research concept with limited or no literature that has direct bearing to the subject, it may be out of place to readily see a perfect alignment with existing works. However, in his 2008 book titled Internet \& Society, Christian Fuchs did a good job at illustrating the Information Age's Social Theory. He emphasized the ubiquitous nature of the Internet in everyday life and enumerated some of the common application areas as: information searches, trips planning, news grabbing, studies, communication with others, business e-mails, instant messaging, social networking, e-meeting, banking transactions, shopping, civic activities, entertainment, dating, games, buying and selling, etc. He averred that: "the emergence of the Internet has transformed society. In research, this has resulted in a plurality of concepts such as Internet economy, digital democracy, cyberculture, virtual community, cyberlove, eParticipation, eGovernment, eGovernance, online journalism, social software, Web 2.0, and so forth. There is no clear meaning of these terms; some of them remain very vague or contradictory". But, "...The Internet obviously is here to stay" (Fuchs C. 2015). Of importance to this material is his identification of the fact that the internet is here to stay and the emergence of the same physical emotions and associating them with virtual interaction like users feeling of belongingness, sense of satisfaction or fulfilment alongside feeling of lost, disorientedness, dissatisfaction, phobia, boredom, stress, feeling of alienation, lonesome, etc. within the internet environment. These are strong indication of an emergence of a social setting with a new environment that has basic attributes of the natural society in virtually all aspects of human interactions. Although this internet created social setting is a virtual one, people are in reality able to engage in the same socio-cultural, socioeconomic, and socio-political activities that are found in the physical settings with the same satisfaction and feedback parameters at individual and group levels.

Even as the effect of this evolving environment is been felt by everyone, the understanding of its mechanisms and dynamics is not as common. Therefore, if we must make the most of it from all directions, we must also understand its ecosystem mechanisms and their dynamics. I believe the above led to some of the vital questions by Fuchs: "How has this system transformed our lives and our society? What are the positive effects? What are the negative ones? Which opportunities and risks for the development of society and social systems are there?" (Fuchs C. 2015). Certainly, the answers to those questions have potentials to work out some level of understanding of the relationship between the Internet mediated society and driving forces of its ecosystem; this also may be useful in figuring out the best ways that this emerging society is shaping itself in order for us to enhance our efficiency, minimize associated risks and maximize our opportunities. The above appears to be what this article 'Operation Mechanism of the Driving Force System of Ecosystem of Cyber-Society Based on the System Dynamics' is aligning to.

\section{Conclusion}

In reviewing this article (Operation Mechanism of the Driving Force System of Ecosystem of Cyber-Society Based on the System Dynamics), a summary of its goals, achievements and presentation appraisal has been provided. This can be summed as creating a better understanding of the operations and dynamics of the driving forces systems of cybersociety ecosystem based on system dynamics approach. Using System Dynamics theory, the paper delivered a theoretical framework of the driving force system of Ecosystem of Cybersociety with an explanation of its operation mechanism. The paper also affirmed the fact that the cyber ecosystem is made of a mixture of participants that interact for multiple purposes just as in the natural ecosystems of the physical society. The article's content, structure, relevance, novelty of the idea, alignment with current research and development interests in the subject area of Cybersociety, and also the article's strengths and limitations were critically analyzed. The article's contribution to the body of knowledge is evident in the novelty of its ideas as expressed, and its set goals of exploring understanding of the functioning of the driving forces for a healthy, resilient, more efficient and satisfying cybersociety ecosystem aimed at enabling preventive and defensive courses of action to be coordinated within and among communities of devices and users. 
As concluding remark, my observation however is as follows: Presently, the key driving forces of the ecosystem of cybersociety are encapsulated in the contemporary ICT innovations, ubiquitous personal and mobile communication devices, affordability and accessibility of the internet, the global trend of computerization that has inadvertently enforced compulsory layering of essential government, public, commercial and social services on the internet as the primary communication, transaction and interaction media; this is in addition to the user-friendly social networking solutions, and the society's unbridled embrace of technology as a way of life in the information age. All of these appear to be working seamlessly but at a state of self-regulated equilibrium like fluid that naturally finds its level and course in the midst of other constrains within its containing frame or elevated boarders being the larger society of users. Therefore, as the world continues to thrive in ICT innovations and internet-mediated globalization manifested in seamless communication, limitless transactions, boundless human interactivities and collaborations, what will be most significant among the driving forces will be the cyberspace users' efforts towards self-regulating their habits or addictions. This is particularly as everyone will be under some sort of naturally occurring but subtle socioeconomic and socio-cultural pressures to metamorphose his/her living essentials and lifestyle into the cybersociety dictates in order to be able to truly live in the physical environment. As the traditional society settings continue to disappear into the emerging cybersociety, it will come to a time when nobody can appropriately fit into the society and experience proper living without succumbing to the dictate of the cybersociety ecosystems. Cybersociety has indeed come to stay, the society is fast changing, the ancient socio-cultural landmarks are being removed, everything is changing in the speed of technology, including the societal structures, processes, and the people.

\section{Reference}

[1]. Elsevier.com (2017), About Elsevier; accessed from: https://www.elsevier.com/about

[2]. en.wikipedia.org (2016) Elsevier; accessed from: https://en.wikipedia.org/wiki/Elsevier

[3]. Gueorguieva V. (2011), Subcultures as Virtual Communities; available at: http://revues.mshparisnord.org/seminarbg/index.php?id=110

[4]. Guan X., Zhang Z., and Zhang S. (2013) Operation Mechanism of the Driving Force System of Ecosystem of Cyber-society Based on the System Dynamics; INT J COMPUT COMMUN, ISSN 1841-9836 8(6):812-824, December, 2013.

[5]. Hartijasti Y. \& Fathonah N. (2015), MOTIVATION OF CYBERLOAFERS IN THE WORKPLACE ACROSS GENERATIONS IN INDONESIA; available at: https://www.researchgate.net/publication/279216671_MOTIVATION_OF_CYBERLOAFERS_IN_THE_WORKP LACE_ACROSS_GENERATIONS_IN_INDONESIA

[6]. Misra S. and Stokols D. (2012), A TYPOLOGY OF PEOPLE - ENVIRONMENT RELATIONSHIPS IN THE DIGITAL AGE; Technology in Society; available at: https://www.researchgate.net/publication/256987533_A_typology_of_people-

environment_relationships_in_the_Digital_Age

[7]. Tran V-D. and Huynh N. D. T. (2015), EXPLORING THE RELATIONSHIPS AMONG SOCIAL BENEFITS, ONLINE SOCIAL NETWORK DEPENDENCY, SATISFACTION, AND YOUTH'S HABIT FORMATION; Available at

https://www.researchgate.net/publication/288468186_EXPLORING_THE_RELATIONSHIPS_AMONG_SOCIAL _BENEFITS_ONLINE_SOCIAL_NETWORK_DEPENDENCY_SATISFACTION_AND_YOUTH\%27S_HABIT _FORMATION 